
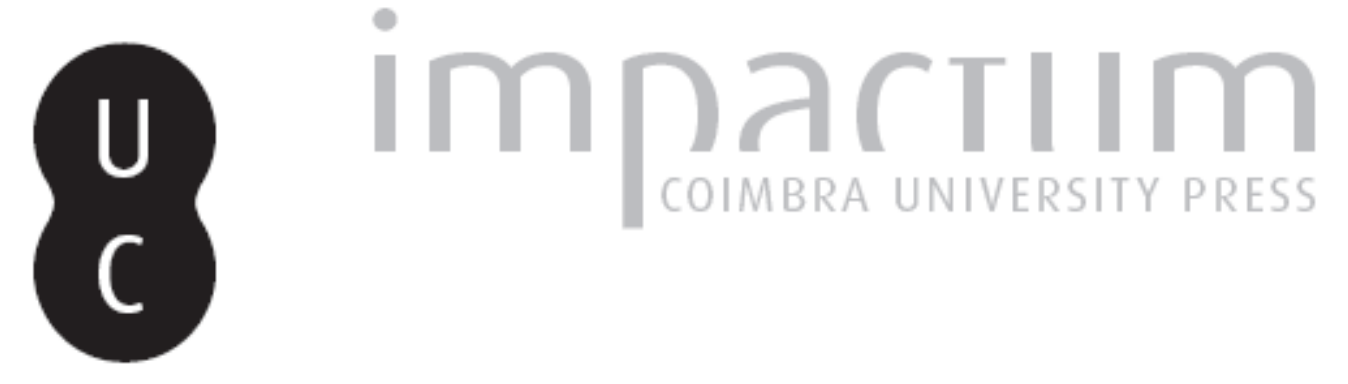

\title{
"Peregrinação" de Fernão Mendes Pinto: o livro do deslumbramento
}

Publicado por: Imprensa da Universidade de Coimbra

URL

persistente:

URI:http://hdl.handle.net/10316.2/43037

DOI:

DOI:https://doi.org/10.14195/1647-8436_46_47_15

Accessed : $\quad$ 26-Apr-2023 14:42:35

A navegação consulta e descarregamento dos títulos inseridos nas Bibliotecas Digitais UC Digitalis, UC Pombalina e UC Impactum, pressupõem a aceitação plena e sem reservas dos Termos e Condições de Uso destas Bibliotecas Digitais, disponíveis em https://digitalis.uc.pt/pt-pt/termos.

Conforme exposto nos referidos Termos e Condições de Uso, o descarregamento de títulos de acesso restrito requer uma licença válida de autorização devendo o utilizador aceder ao(s) documento(s) a partir de um endereço de IP da instituição detentora da supramencionada licença.

Ao utilizador é apenas permitido o descarregamento para uso pessoal, pelo que o emprego do(s) título(s) descarregado(s) para outro fim, designadamente comercial, carece de autorização do respetivo autor ou editor da obra.

Na medida em que todas as obras da UC Digitalis se encontram protegidas pelo Código do Direito de Autor e Direitos Conexos e demais legislação aplicável, toda a cópia, parcial ou total, deste documento, nos casos em que é legalmente admitida, deverá conter ou fazer-se acompanhar por este aviso. 


\section{BOLETIM DA \\ BIBLIOTECA GERAL DA UNIVERSIDADE DE COIMBRA}

VOL. 46/47 (2015/2016)

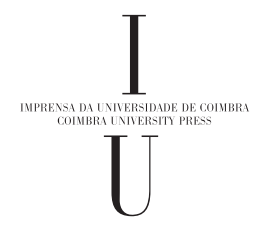




\title{
“Peregrinação" de Fernão Mendes Pinto : o livro do deslumbramento
}

\author{
Biblioteca Joanina, de março a junho de 2014 \\ Sala do Catálogo da BGUC, janeiro de 2015
}

\section{Séculos XVII e XVIII}

PINTO, Fernão Mendes, 1514?-1583

Peregrinaçam de Fernam Mendez Pinto, em que da conta de muytas e muyto estranhas cousas que vio \& ouvio no reyno da China, no da Tartaria , no do Sarnau, que vulgarmente se chama Sião, no do Calaminhan, no de Pegù, no de Martauão, \& em outros muytos reynos \& senhorios das partes Orientais, de que nestas nossas do Occidente ha muyto pouca ou nenhu[m]a noticia. E tambem da conta de muytos casos particulares que acontecerão assi a elle como a outras pessoas ... Em Lisboa : por Pedro Crasbeeck : a custa de Belchior de Faria, 1614. V.T.-9-7-1

$1-6-22-500$

Historia oriental de las peregrinaciones de Fernan Mendes Pinto ... a donde se escriven muchas, y muy estrañas cosas que viò, oyò en los reynos de la China, Tartaria, Sornao, que vulgarmente se llama Siã, Calamiñam, Peguu, Martauan, y otros muchos de aquellas partes Orientales, de que en estas nuestras de Occidente ay muy poca, ò ninguma noticia ... Traducido de portugues en castellano por el Licenciado Francisco de Herrera Maldonado ... Madrid : Tomas Iunti, 1620.

V.T.-9-7-1a 
Les voyages advantureux de Fernand Mendez Pinto. Fidellement traduits de portugais en françois par le sieur Bernard Figuier ... A Paris : chez Arnould Cotinet et chez Jean Roger, 1645.

$1-6-21-449$

Historia oriental de las peregrinaciones de Fernan Mendez Pinto ... a donde se escriven muchas, y muy estrañas cosas que viò, oyò en los reynos de la China, Tartaria, Sornao, que vulgarmente se llama Siã, Calamiñam, Peguu, Martauan, y otros muchos de aquellas partes Orientales, de que en estas nuestras de Occidente ay muy poca, ò ninguma noticia ... Traducido de portugues en castellano por el Licenciado Francisco de Herrera Maldonado ... [4a ed. castelhana]. En Madrid : por Melchor Sanchez : a costa de Mateo de la Bastida mercader de libros, vendese en su casa frontero a las grades de San Felipe, 1664.

$1-6-22-499$

Peregrinaçam de Fernam Mendez Pinto, e por elle escrita que consta de muitas, e muito estranhas cousas que vio \& ouuio no reyno da China, no de Tartaria, no de Pegú, no de Martauão, \& em outros muytos reynos $\&$ senhorios das partes Orientaes, de que nestas nossas do Occidente ha muyto pouca ou nenhu[m]a noticia. E tambem da conta de muytos casos particulares que acontécerão assim a elle como a outras muytas pessoas... Em Lisboa : na officina de Antonio Craesbeeck de Mello ... impressa â sua custa, 1678.

$1-6-22-498$

Peregrinaçaõ de Fernaõ Mendes Pinto, e por elle escrita que consta de muitas, e muy estranhas cousas que vio, e ouvio no Reyno da China, no da Tartaria, no do Pegú, no de Martavaõ, e em outros muitos reynos, e senhorios das partes orientaes ... e no fim della trata brevemente de algu[m]as noticias e da morte do Santo Padre Mestre Francisco Xavier ... Agora novamente correcta, e emendada. Accrecentada com o Itenerario de Antonio Tenreiro ... e a conquista do reyno de Pegu feita pelos Portuguezes no anno de 1601,... Lisboa : na officina de Joam de Aquino Bulhoens : á custa de Luiz de Moraes, 1762.

S.P.-Ah-8-14 


\section{Edições completas}

PINTO, Fernão Mendes, 1514?-1583

Peregrinação. Edição popular com uma noticia, notas e glossario por J. I. de Brito Rebello. Lisboa : Livraria Ferreira, 1908-1910. (Livros de oiro da literatura portuguêsa)

9-(4)-1-9-23/26

Peregrinação. Nova edição, conforme a de 1614; precedida de uma notícia bio-bibliográfica por Jordão de Freitas. Vila Nova de Gaia : Cosmópolis, 1930-1931.

9-(4)-2-5-3/4

Peregrinação. Nova edição, conforme a de 1614, preparada e organizada por A. J. da Costa Pimpão e César Pegado. Porto : Portucalense Editora, 1944-1945. (Colecção de memórias e notícias ultramarinas)

9-(4)-3-7-5

910.42(5)"15" PIN

Peregrinaçam: texto primitivo, inteiramente conforme à primeira edição (1614) = Peregrinação: versão integral em português, seguida das suas Cartas. Versão integral em português moderno por Adolfo Casais Monteiro. Lisboa; Rio de Janeiro : Sociedade de Intercâmbio Cultural Luso-Brasileiro: Livraria-Editora da Casa do Estudante do Brasil, 1952-1953.

9-(4)-7-1-10/11

Peregrinação e outras obras. Texto crítico, prefácio, notas e estudo por António José Saraiva. 1a ed. Lisboa : Sá da Costa, 1961-1962. (Clássicos Sá da Costa)

5-72-4-18/19

Peregrinação. Versão para português actual de Maria Alberta Menéres. [1ª edição]. Lisboa : Ed. Afrodite, 1971. (Clássicos)

6-34-13

5-43-9 (2a ed. - [Lisboa], 1975-1979) 
Peregrinação de Fernão Mendes Pinto. Itinerário de António Tenreiro. Tratado das cousas da China [Gaspar da Cruz]. Conquista do Reino de Pegu [Manuel de Abreu Mouzinho] ; Introdução de Aníbal Pinto de Castro. Porto : Lello \& Irmão, 1984. (Tesouros da literatura e da história) 5-52-47

Peregrinação ; \& Cartas. Comentários críticos de Eduardo Lourenço ... [et al.]; versão para português actual e glossário de Maria Alberta Menéres. Lisboa : Afrodite, 1989.

$5-10-66-1 / 2$

Carta del hermano Hernan mendez dela compañia de lesus dela India para los padres y hermanos dela misma compañia en Portugal. In Copia de unas cartas de algunos padres y hermanos dela compañia de lesus que escriuieron dela India, lapon y Brasil alos padres y hermanos dela misma compañia en Portugal ... fuerõ recebidas el año de mil y quinientos y cincuenta y cinco. [Coimbra] : por loan Aluarez, 13 Deziember [sic] 1555. f. [7v-12].

RB-7-7

Fernão Mendes Pinto and the Peregrinação : studies, restored portuguese text, notes and indexes. Edited by Jorge Santos Alves; transl. and proofreading Kevin Rose and Richard Trewinnard. Lisbon : Imprensa Nacional-Casa da Moeda : Fundação Oriente, 2010. (Biblioteca de autores portugueses)

10-(1)-5-21-53

\section{Adaptações}

PINTO, Fernão Mendes, 1514?-1583

Em busca do corsário (Da Peregrinação). Rio de Janeiro : Annuario do Brasil, 1920. (Anthologia Universal)

7-24-1-23 
A ilha dos tesouros (Da peregrinação). Rio de Janeiro : Annuario do Brasil, 1921. (Anthologia Universal)

7-24-1-27

Peregrinação: excertos. Edição organizada por José Tavares. Porto : Lello \& Irmão ; Lisboa : Aillaud \& Lellos, [1928]. (Colecção Lusitânia ; 64, 65) 9-(11)-23-1-41/42

6-40-16-13/14 (Porto, 1971)

Peregrinação: aventuras extraordinárias dum português no Oriente. Adaptação de Aquilino Ribeiro; Il. de Martins Barata. [1 ${ }^{\text {a }}$ ed.]. Lisboa : Livraria Sá da Costa, 1933. (Os grandes Livros da Humanidade ; 3)

$5-21-20$

Peregrinação : episódio da busca do corsário Coja Acem. Prefácio e notas de António Sérgio. Lisboa, 1938. (Textos Literários. Autores Portugueses) $6-6-22-82$

A ilha maravilhosa de Catemplui da "Peregrinação" de Fernão Mendes Pinto. [ed. de Luís de Montalvor] ; Litografias originais e aguarelas de Mily Possoz. Lisboa : Editorial Ática, 1944.

RB-5-5

V.T.-14-7-8

Peregrinação. Selecção, prefácio e notas de Rodrigues Lapa. Lisboa : Gráfica Lisbonense, 1946. (Textos Literários)

5-39-14

No rasto do corsário. Adaptação ao português moderno por Branquinho da

Fonseca. Lisboa : Portugália Editora, [1962?]. (Biblioteca dos Rapazes ; 46) 5-66-42-12

9-(1)-11-23-36 (1a ed. fac-simile - Lisboa, 2009)

Peregrinação. Lisboa : Amigos do Livro, [1974?]

5-46-89 
A "Peregrinação" de Fernão Mendes Pinto: autobiografia e aventura na literatura de viagens. Apresentação crítica, selecção, resumos, glossário e sugestões para análise literária de João David Pinto Correia. Lisboa : Seara Nova, 1979. (Colecção Textos Literários ; 13)

$5-9-42-74$

Peregrinação [de] Fernão Mendes Pinto: aventuras de um português ... contadas aos jovens por Adolfo Simões Müller; II. de José Ruy. Mem Martins : Europa-América, 1980. (Os grandes clássicos juvenis)

6-17-26-3

Nesta caravela me embarquei eu ... adaptação Peregrinação Fernão Mendes Pinto. Projecto e ilustração Ernesto Neves; selecção e adaptação de textos Branca Judith, M. Lalande. [Maia] : Castoliva, 1983. (Portugueses no mundo)

5-17-19-7

E tais pancadas tem a costa da China : peregrinação. Versão de Maria Alberta Menéres. Lisboa : EXPO 98, 1997. (98 mares ; 36)

6-40-17-90

Peregrinação [de] Fernão Mendes Pinto. Narrativa adaptada [por] Fernando Cardoso; il. Pedro Sousa Dias, Cristina Souza. $1^{\text {a }}$ ed., $1^{\text {a }}$ tir. Porto : Areal, 1999.

6-66-21-83

Peregrinação [de] Fernão Mendes Pinto. Condensação e adaptação de Teresa Bernardino a partir da selecção de Adolfo Casais Monteiro; il. Luís Anglin. Lisboa : Verbo, imp. 2000. (O prazer de ler. Clássicos juvenis ; 1) 9-1-50-1

Peregrinação de Fernão Mendes Pinto: aventuras extraordinárias de um português no Oriente. Adaptação por Aquilino Ribeiro; il. de André Letria. 14ª ed. Lisboa : Sá da Costa, 2008. (Clássicos da humanidade)

5-72-5-22 
Peregrinação de Fernão Mendes Pinto: aventuras extraordinárias de um português no Oriente. Adaptação por Aquilino Ribeiro; il. de Pedro Rosa. Lisboa : Bertrand, 2009.

9-(1)-5-57-31

RIBEIRO, Aquilino, 1885-1963

Portugueses das sete partidas (viajantes, aventureiros, troca-tintas). Il. de João da Câmara Leme. Lisboa : Livraria Bertrand, 1969. (Obras completas de Aquilino Ribeiro).

5-36-8

DOMINGUES, Mário, 1899-1977

Fernão Mendes Pinto. Il. de António Domingues. Porto : [s.n., 19--?]

$5-46-42-41$

BARROQUEIRO, Deana, 1945-

O corsário dos sete mares: Fernão Mendes Pinto: [romance]. Deana Barro-

queiro ; rev. José Eduardo Didier. $1^{\text {a }}$ ed. Alfragide : Casa das Letras, 2012. 10-(1)-8-17-22

\section{Traduções}

PINTO, Fernão Mendes, 1514?-1583

The voyages and adventures of Ferdinand Mendez Pinto, the Portuguese.

Done into English by Henry Cogan; with an introduction by Arminius Vambéry. An abridged and illustrated edition. London : T. Fisher Unwin, 1891. 9-(5)-3-5-28

Peregrinazione 1537-1558 di Fernão Mendes Pinto. A cura di Giuseppe Carlo Rossi; traduzione di Erilde Melillo Reali. Milano : Longanesi, 1970. (I Cento viaggi ; 9)

$5-5-23$ 
The travels of Mendes Pinto. Edited and translated by Rebecca D. Catz.

Chicago ; London : The University of Chicago Press, 1989.

7-75-14-40

9-(11)-28-3-26

Pérégrination: récit de voyage. Traduit du portugais et présenté par Robert

Viale. Paris : Editions de la Différence, imp. 1991.

7-75-19-44

Pelgrimsreis. Vertaald door Arie Pos. Baarn : de Prom, cop. 1992.

5-4-15

ANGELE, Martin, 1961

Peregrinação oder Die Reisen des Fernão Mendes Pinto. Norderstedt : Books on Demand GmbH, 2004.

7-49 A-15-50

\section{Bibliografia passiva}

AIRES, Cristóvão, 1853-1930

Fernão Mendes Pinto : subsidios para a sua biographia e para o estudo da sua obra. História e memórias da Academia Real das Sciencias de Lisboa. $2^{a}$ classe, Sciencias moraes, politicas e bellas lettras. Lisboa. $10: 1$ (1905) 1-127 + 2 mapas.

A-29-34

LE GENTIL, Georges, 1875-1953

Fernão Mendes Pinto: un précurseur de l'exotisme au XVle siècle. Paris : Hermann, 1947. (Les Portugais en Extrême Orient) 869.0.06 Pinto LEG

COLLIS, Maurice, 1889-1973

The Grand peregrination: being the life and adventures of Fernão Mendes

Pinto. London : Faber and Faber, 1949.

5-43-36 
CATZ, Rebecca, 1920-

Fernão Mendes Pinto: Sátira e anti-cruzada na Peregrinação. 1ª ed. Lisboa : Instituto de Cultura e Língua Portuguesa, 1981. (Biblioteca Breve ; 57. Série Literatura)

9-(11)-17-1-45

CATZ, Rebecca, 1920-

Fernao Mendes Pinto in foreign literature. Lisboa : Instituto de Cultura e Língua Portuguesa, 1987. Sep. de "Congresso sobre a Situação Actual da Língua Portuguesa no Mundo", Lisboa, 2, 1983. Vol. 2, p. 445-457.

6-10-2-36

LOURENÇO, Eduardo, 1923-

O livro do deslumbramento. Oceanos. Itália. N. 7 (Jul. 1991), p. 58-61. A-26-47

CASTRO, Aníbal Pinto de, 1938-2010

De Montemor-o-Velho às ilhas do Japão : a Peregrinação de Fernão Mendes Pinto e o encontro de culturas = From Montemor-o-Velho to the islands of Japan : the Peregrinação of Fernão Mendes Pinto and the meeting of cultures. Pref. Manuel Viegas Abreu. Coimbra : Comissão de Coordenação da Região Centro, 1993.

5-54-47-93

MORAIS, Venceslau de, 1854-1929

Fernão Mendes Pinto no Japão. Prefácio de Daniel Pires. [3ª ed.]. Lisboa :

Vega, 1993. (Mnésis ; 16) (Clássicos da literatura portuguesa) 6-66-17-13

MARQUES, Alfredo Pinheiro, 1956-

Fernão Mendes Pinto, do Mondego ao Japão: escapar da maldição e da miséria, e lavrar o epitáfio do Império = Fernão Mendes Pinto, from Mondego to Japan: escaping from curse and misery, and carving the epitaph of Empire. Trad. Diana Helena dos Santos Alves. Montemor-o-Velho : Casa-Museu Infante Dom Pedro [etc.], 2002.

8-(2)-19-39-36 
ALMEIDA, Fernando António, 1939-

Fernão Mendes Pinto em terras de Almada. Almada : Câmara Municipal, 2010.

10-(1)-11-21-90

LOUREIRO, Rui, 1955-

Mission impossible: in search of the sources of Fernão Mendes Pinto's Peregrinação. In Fernão Mendes Pinto and the Peregrinação: studies, restored portuguese text, notes and indexes. Edited by Jorge Santos Alves; transl. and proofreading Kevin Rose and Richard Trewinnard. Lisbon : Imprensa Nacional-Casa da Moeda : Fundação Oriente, 2010. (Biblioteca de autores portugueses). Vol. 1, p. 235-255. $10-(1)-5-21-52$ 